\title{
Ernest Solvay, serendipity, and environments for innovation
}

\author{
Tam-Tri Le, Minh-Hoang Nguyen \\ Centre for Interdisciplinary Social Research \\ Phenikaa University, Hanoi, Vietnam \\ 2022 January 25 \\ OSF Preprints
}

Ernest Gaston Joseph Solvay (1838-1922) was a Belgian chemist and industrialist. In 1861, the major serendipity moment came when he obtained sodium carbonate (soda ash - $\mathrm{Na}_{2} \mathrm{CO}_{3}$ ) after mixing table salt with ammonia and carbonic acid gas in his experimentation room. This later led to the well-known "Solvay process" of producing soda ash from inexpensive and widely available resources of brine (source of sodium chloride - $\mathrm{NaCl}$ ) and limestone (source of calcium carbonate - $\left.\mathrm{CaCO}_{3}\right)$ with recyclable ammonia $\left(\mathrm{NH}_{3}\right)$ as the "catalyst". Solvay was unaware that other chemists had described the reaction. Industrial applications had been attempted to certain degrees, which turned out to be a good thing as he established his company in 1863. The company had a rocky start (even came close to bankruptcy). However, Solvay stuck to his vision and began large-scale production in 1865 while continuing to improve the technical aspect of the process. Solvay reaped immense success in 1870-1880 and expanded production to an international scale. In 1900, $95 \%$ of soda ash consumed worldwide was produced using the Solvay process. In 2020 , the company had a net sales of $€ 8.9$ billion. Looking back, we can see that the chemical discovery in 1861 became a crucial serendipity moment in relation to the huge success of Solvay. Still, this relative value emerged conditionally due to his particular mindset and direction of actions. Otherwise, the discovery would simply stay at the level of chemistry curiosity and would not turn into the impactful industrial innovation we witness through history.

Suppose we wonder what conditions made Ernest Solvay become the person he was; we should also look at the efforts he put in trying to create such conditions for other generations of innovators. Solvay was not just a talented scientist and a brilliant entrepreneur. He was also a great philanthropist who significantly contributed to improving the global science culture using financial power from his business. In 1902, he founded the Solvay Institute of Sociology (Institut de Sociologie Solvay) and, in 1903, the Solvay Business school (École de Commerce Solvay). In 1911, the first Solvay Conference (Conseil Solvay) on "Radiation and the Quanta" was held, chaired by Hendrik Lorentz and attended by the world's most important brains such as Albert Einstein, Marie Curie, Ernest Rutherford, Henri Poincaré, and Max Planck.

From this first success, Solvay founded the International Solvay Institute for Physics in 1912 and the International Solvay Institute for Chemistry in 1913; the two later merged into the International Solvay Institutes for Physics and Chemistry, which has been organizing the Solvay Conference once every two years up to the present day. The fifth Solvay Conference on Physics held in 1927 on "Electrons and Photons" was an important milestone for quantum theory research, with notable names among participants such as Niels Bohr, Werner Heisenberg, Erwin Schrödinger, and Paul Dirac. Solvay Conferences have largely been considered the most famous conferences in physics 
and chemistry, where great minds of the world meet and discuss current major problems, leading to the innovation of immense values to the advancement of humanity during the last century.

Environments for innovation are built from the great efforts of scientists and many others. Such environments can facilitate information reception, filtering, generation, and exchange following the mindsponge mechanism (Nguyen et al., 2021; Q. H. Vuong, 2016; Q. H. Vuong \& Napier, 2015). Here, valuable serendipity moments may happen easier (Cunha et al., 2010; Napier \& Vuong, 2013), and the culture of science also support the 3D process of creativity (Q. H. Vuong \& Napier, 2014). The serendipity-mindsponge-3D framework can be seen through recent innovations regarding the development and production of COVID-19 vaccines (Q.-H. Vuong et al., 2022). Additionally, this shows how much it takes to create and maintain a healthy scientific system, especially in developing countries (Q.-H. Vuong, 2018, 2019).

\section{References}

Cunha, M. P. e, Clegg, S. R., \& Mendonça, S. (2010). On serendipity and organizing. European Management Journal, 28(5), 319-330. https://doi.org/10.1016/j.emj.2010.07.001

Napier, N., \& Vuong, Q. H. (2013). Serendipity as a Strategic Advantage? In T. Wilkinson (Ed.), Strategic Management in the 21st Century (pp. 175-199). Praeger/ABC-Clio. https://scholarworks.boisestate.edu/internationalbusiness_facpub/16

Nguyen, M.-H., et al. (2021). Alice in Suicideland: Exploring the Suicidal Ideation Mechanism through the Sense of Connectedness and Help-Seeking Behaviors. International Journal of Environmental Research and Public Health, 18(7), 3681. https://doi.org/10.3390/ijerph18073681

Vuong, Q. H. (2016). Global Mindset as the Integration of Emerging Socio-Cultural Values Through Mindsponge Processes: A Transition Economy Perspective. In J. Kuada (Ed.), Global Mindsets: Exploration and Perspectives (pp. 109-126). Routledge. https://doi.org/10.4324/97813157363968

Vuong, Q. H., \& Napier, N. K. (2014). Making creativity: The value of multiple filters in the innovation process. International Journal of Transitions and Innovation Systems, 3(4), 294-327. https://doi.org/10.1504/IJTIS.2014.068306

Vuong, Q. H., \& Napier, N. K. (2015). Acculturation and global mindsponge: An emerging market perspective. International Journal of Intercultural Relations, 49, 354-367. https://doi.org/10.1016/j.jintrel.2015.06.003

Vuong, Q.-H. (2018). The (ir)rational consideration of the cost of science in transition economies. Nature Human Behaviour, 2(1), 5. https://doi.org/10.1038/s41562-017-0281-4

Vuong, Q.-H. (2019). Breaking barriers in publishing demands a proactive attitude. Nature Human Behaviour, 3(10), 1034. https://doi.org/10.1038/s41562-019-0667-6

Vuong, Q.-H., et al. (2022). Covid-19 vaccines production and societal immunization under the serendipity-mindsponge-3D knowledge management theory and conceptual framework. Humanities and Social Sciences Communications, 9, 22. https://doi.org/10.1057/s41599-02201034-6 